Reflective and impulsive processes underlying saving behaviour and the additional roles of self-control and habit

(C) 2018, American Psychological Association. This paper is not the copy of record and may not exactly replicate the final, authoritative version of the article. Please do not copy or cite without authors permission. The final article will be available, upon publication, via its DOI: $10.1037 /$ npe 0000093

Full citation: Allom, V., Mullan, B. A., Monds, L., Orbell, S., Hamilton, K., Rebar, A., \& Hagger, M. S. (2018). Reflective and impulsive processes underlying saving behaviour and the additional roles of self-control and habit. Journal of Neuroscience, Psychology, and Economics. doi: $10.1037 /$ npe0000093 


\begin{abstract}
Using a dual-process framework, the aim of this research was to investigate the associations between reflective and impulsive processes and saving behaviour. Self-control and saving habit were tested as additional factors that potentially moderate the relationship between constructs representing reflective and impulsive processes and behaviour or exert indirect effects on behaviour through these systems. A community sample of 594 participants completed measures of saving intention, buying impulsiveness, trait self-control, saving automaticity, and propensity to save money. A well-fitting variance-based structural equation model, $\mathrm{GoF}=0.338 ;$ APC $=.119, p<.001$, accounted for statistically significant amounts of variance in the key dependent variables: intention to save, $R^{2}=.364$, buying impulsiveness, $R^{2}=.232$, and saving behaviour, $R^{2}=.173$. Self-control and saving habit were indirectly related to saving behaviour through intention, and buying impulsiveness was directly related to behaviour when saving habits were low. Findings indicate strong saving habits may help to protect against impulsive spending and offer several targets for interventions aimed at improving saving behaviour.
\end{abstract}

Keywords: Saving; dual-process; self-control; habit, impulsivity JEL classification: D12 


\section{Reflective and impulsive processes underlying saving behaviour and the additional roles of self-control and habit}

\section{Introduction}

Saving refers to the restraint of consumption to safeguard future living (Wärneryd, 1999). Typically, this involves saving money to gain financial security. The benefits of engaging in saving behaviour include societal-level outcomes such as allowing for consumption during periods of recession (Wärneryd, 1999), interpersonal outcomes such as family stability and wellbeing (Dew, 2016; Fisher \& Anong, 2012; Yuh \& Hanna, 2010), and individual level outcomes such as improved mental and physical health (Shim, Serido, \& Tang, 2012). At the individual level, a meta-analysis examining the relationship between personal debt (student loans and credit card debt) and both mental and physical health outcomes demonstrated that higher personal debt was associated with greater risk of depression and suicide contemplation, and of engaging in health risk behaviours such as problem drinking and substance abuse (Richardson, Elliott, \& Roberts, 2013). More recently, a meta-analysis found that personal debt (e.g., home loans, student loans, and credit card debt) has a negative influence on overall subjective wellbeing (Tay, Batz, Parrigon, \& Kuykendall, 2016). Given the significance of these outcomes related to saving behaviour, it is important to examine the determinants of saving behaviour to inform interventions aimed at promoting this behaviour.

Previous research focused on identifying the correlates of saving behaviour has largely focused on demographic (Fisher, 2010; Grable \& Lytton, 1997; Yuh \& DeVaney, 1996) or societal factors (Blau, 1994). While these factors are important, the majority are not readily modifiable and do not explain the complexity of influences that underpin saving behaviour. An approach that focuses on psychological factors informed by a relevant theoretical framework may result in the identification of more meaningful intervention 
targets. Previous research that has focused on the psychological correlates of individual level saving behaviour rarely does so within a theoretical framework (Hershey, Jacobs-Lawson, McArdle, \& Hamagami, 2007; Stawski, Hershey, \& Jacobs-Lawson, 2007), or has done so but with some limitations (Davis \& Hustvedt, 2012; Kidwell \& Turrisi, 2004; Magendans, Gutteling, \& Zebel, 2016; Shim et al., 2012; Wärneryd, 1999). Of the psychological theories that have been applied to explain saving behaviour, the theory of planned behaviour has featured prominently (Ajzen, 1991). The primary assumption of the theory is that intention leads to behaviour. However, many studies on saving behaviour have focused solely on the prediction of intention rather than behaviour (Kidwell \& Turrisi, 2004; Rabinovich \& Webley, 2007). This is problematic considering the acknowledged intention-behaviour 'gap', in which forming an intention does not always result in behaviour change (Kothe, Mullan, Sainsbury, \& Smith, 2015; Orbell, 2007). This is reflected by the consistent findings that the theory of planned behaviour is effective in predicting intention but less successful in predicting behaviour (McEachan, Conner, Taylor, \& Lawton, 2011; Rich, Brandes, Mullan, \& Hagger, 2015; Sniehotta, Presseau, \& Araújo-Soares, 2014), and that factors other than intention also determine behaviour and influence the relationship between intention and behaviour (Hamilton, Kirkpatrick, Rebar \& Hagger, 2017; Juraskova et al., 2012; Mullan, Henderson, Kothe, Allom, Orbell \& Hamilton, 2016; Sniehotta et al., 2014).

Dual-process theories offer a more complete account of behaviour as they extend behavioural explanation beyond factors representing reflective processes (i.e., intention) to consider the role of automatic processes in determining behaviour (Hofmann, Friese, \& Wiers, 2008; Strack \& Deutsch, 2004; Alós-Ferrer \& Strack , 2014). Models that take this approach suggest that behaviour is driven by two systems: reflective and impulsive. The reflective system is represented by controlled processes, conscious deliberation and goals. The impulsive system, on the other hand, is represented by automatic tendencies and 
associative processes. An impulsive factor that may be particularly influential in the context of saving behaviour is buying impulsiveness. This term refers to sudden and immediate spending of money with no prior intention to do so (Beatty \& Ferrell, 1998) and is characterised as a response to an overwhelming urge that may override intention (Bayley \& Nancarrow, 1998). Dual-process explanations of saving behaviour would suggest that an individual's intention to save money and their impulse to spend money may compete with each other to direct behaviour; however, the influence of these systems may depend upon additional factors (Strack, Werth, \& Deutsch, 2006), and these factors may also operate indirectly on behaviour through the respective systems.

For example, self-control, defined as the ability to regulate cognition, emotion and behaviour in line with long-term goals (Baumeister, Vohs, \& Tice, 2007) has been shown to relate directly to a variety of beneficial behaviours (Tangney, Baumeister, \& Boone, 2004) and also plays a role in determining which system directs behaviour (Hofmann, Friese, \& Strack, 2009; Mullan, Allom, Brogan, Kothe, \& Todd, 2014). Specifically, behaviour is more likely to be controlled by reflective processes, represented by effects of intention on behaviour, in people with greater self-control (Allom \& Mullan, 2012; Allom, Mullan, Clifford \& Rebar, 2017). Analogously, when self-control capacity is low, behaviour tends to be controlled by more impulsive tendencies (Allom, Panetta, Mullan, \& Hagger, 2016; Black, Mullan \& Sharpe, 2017; Friese \& Hofmann, 2009). Vohs and Faber (2007) demonstrated that among individuals who had completed a task designed to exhaust self-control; those who were high in buying impulsiveness were more likely to spend money than those lower in buying impulsiveness. Similarly, Achtziger and colleagues demonstrated that self-control significantly predicted compulsive buying behaviour, such that individuals with high levels of self-control were less likely to report problems with compulsive buying than individuals with low levels of self-control (Achtziger, Hubert, Kenning, Raab \& Reisch, 2015). Low levels of 
self-control have also been shown to predict over-indebtedness (Gathergood, 2012). Thus, self-control appears to be an important factor which influences whether reflective or impulsive factors drive saving behaviour.

Habit represents another factor that is likely to be an important determinant of saving behaviour. A habit is an automatic action that is triggered by a cue as a consequence of repeated action in association with the cue in the past, and may occur outside conscious awareness (Gardner, 2015; Hagger, Rebar, Mullan, Lipp, \& Chatzisarantis, 2015; Lally, Wardle, \& Gardner, 2011). While saving behaviour is often thought to be a highly deliberative process (e.g., deciding to save for a car), smaller financial decisions also occur frequently throughout the day (e.g., deciding what to order at a restaurant; Prelec \& Loewenstein, 1991). If individuals continually choose budget-friendly options in these circumstances, and these circumstances are frequently repeated, saving habits may subsequently develop and other saving behaviours may then operate as a function of habit (Loibl, Kraybill, \& DeMay, 2011). For example, Loibl et al. (2011) demonstrated that habit accounted for unique variance in saving behaviour when included as a predictor of saving behaviour alongside intention. This suggests that habits predict behaviour independent of intentions, which points to separate roles for deliberative processes, represented by intentions, and implicit processes represented by habit. Furthermore, habit has been found to moderate the strength of the relationship between constructs representing reflective processes, like intention, and behaviour. The inclusion of saving habits in the prediction of saving behaviour may, therefore, moderate the effect of intention on behaviour (Kothe et al., 2015). The moderation effect is consistent with theory on habit that suggests as actions become increasingly determined by implicit, automatic processes the effect of more deliberative, reflective processes wanes (Bargh, 1994). Thus, habit may act as another conditional factor in 
the dual-process model that influences the relative weight of the two systems governing saving behaviour.

While previous research has suggested that a dual-process model can explain saving behaviour (Strack et al., 2006), few applications of this model have attempted to determine the additional conditions by which the two systems influence behaviour. Moreover, previous research has demonstrated direct effects of additional variables such as self-control and habit on behaviour, and the potential of these factors to moderate the effects of constructs representing the two systems on behaviour (Allom \& Mullan, 2012; Allom, Mullan, Clifford \& Rebar, 2017; Friese, Hofmann, \& Wänke, 2008), but less attention has been given to whether these variables have indirect effects on behaviour through constructs representing the two systems. The aim of the current research was to explore the simultaneous influences of constructs that represent reflective and impulsive processes on saving behaviour, and to determine the conditions under which these constructs guide behaviour by examining the moderating and mediating roles of additional factors related to saving behaviour.

Specifically, it is expected that self-control and saving habits will have indirect effects on saving behaviour through intention and buying impulsiveness such that self-control and saving habit will be positively related to intention and negatively related to buying impulsiveness and these variables will in turn relate to greater and lesser propensity to save money, respectively. It is expected that self-control and saving habit will moderate the relationships between intention and behaviour, and between buying impulsiveness and behaviour. Specifically, we predict that intention will have a stronger relationship with saving behaviour at higher levels of self-control and lower levels of habit, and buying impulsiveness will have a weaker relationship with saving behaviour at higher levels of self-control and saving habits. Finally, given that demographic factors have been found to relate to saving 
behaviour (Grable, 2000), we will control for these factors in the model in order to determine the unique contribution of psychological factors to saving behaviour.

\section{Materials and Methods}

\subsection{Participants}

Participants $(n=594)$ were from the USA recruited through SocialSci; https://www.socialsci.com/, an online survey development recruitment system. The majority of participants were female (62.0\%), and self-identified as Caucasian (71.2\%). The median income was 40,000 - 49,999 USD per year. Age ranged from 18 - 73 years $(M=31.06$; $S D=$ 10.66). Participants were excluded if they were younger than 18 years old. A 2 USD inconvenience allowance was provided in return for participation in the study.

\subsection{Measures}

2.2.1 Intention. Intention to save money was assessed as the mean of three items (e.g., "I intend to save money”). Participants responded on seven-point Likert scales (1 = strongly disagree; 7 = strongly agree) with higher scores indicating greater intention to engage in saving behaviour. The items demonstrated good reliability, $\alpha=.838$.

2.2.2 Buying impulsiveness. The buying impulsiveness scale (Rook \& Fisher, 1995) was used to assess the tendency for a consumer to spend money spontaneously without forethought. Participants responded to nine items relating to the way they make purchases (e.g., “I often buy things spontaneously’) on five-point Likert scales ( 1 = strongly disagree; 5 = strongly agree). Higher scores indicate a greater tendency towards spending money impulsively. The items demonstrated excellent reliability, $\alpha=.926$.

2.2.3 Self-Control. Self-control was measured using the brief self-control scale (Tangney et al., 2004). Participants indicated the extent to which 13 statements reflected their typical behaviour (e.g., "I am good at resisting temptation”) on five-point Likert scales (1 = 
not at all; 5 = very much). Higher scores indicate greater self-control. The items demonstrated good reliability, $\alpha=.809$.

2.2.4 Habit. Saving habits were assessed by a subset of four items from the selfreport habit index (SRHI) (Verplanken \& Orbell, 2003). Participants responded to the stem “For me, saving money is something...” followed by four statements (e.g., “...that I do without thinking”) on seven-point Likert scales (1 = strongly disagree; 7 = strongly agree) (Gardner, Abraham, Lally, \& de Bruijn, 2012). Higher scores indicate stronger habit towards saving money. The items demonstrated excellent reliability, $\alpha=.964$.

2.2.5 Saving behaviour. Saving behaviour was assessed using the money saving subscales of the propensity to plan scale (Lynch, Netemeyer, Spiller, \& Zammit, 2010). Saving money in the short term was assessed using six items (e.g., "I set financial goals for the next few days for what I want to achieve with my money”). Participants indicated how characteristic of themselves that item was on six-point Likert scales ( $1=$ strongly disagree; 6 = strongly agree). Higher scores indicate a greater tendency to engage in saving behaviours in the short term. Saving money in the longer term was assessed using the same items; however, the time period was changed from "the next few days” to "1-2 months”. Higher scores indicate a greater tendency to engage in saving behaviours in the long term. The items demonstrated excellent reliability, for both the short term $(\alpha=.940)$ and longer term $(\alpha=$ $.958)$ saving scales.

\subsection{Procedure}

The University’s Human Research Ethics Committee approved the study. Participants were recruited online and, after viewing study information, provided consent by clicking the 'I agree' option. Participants then completed the measures in random order at their own pace. These measures were part of a larger online study, which took approximately 30 minutes in total to complete. Upon completion participants were provided with a debrief. 


\subsection{Data analysis}

Data were analysed using variance-based structural equation modelling (VB-SEM), also known as Partial Least Squares analysis, using the Warp PLS v.5.0 statistical software package (Kock, 2015). All latent variables in the structural equation model were indicated by multiple items representing the hypothesised psychological constructs from the intention to save scale, the buying impulsiveness scale, the brief self-control scale, the self-report behavioural automaticity index and the money saving subscales of the propensity to plan scale. The hypothesised relations among the variables in the proposed model were set as free parameters. Gender, age, and income were included as control variables and the effects of these covariates on all other variables in the model were tested.

At the measurement level, construct validity of the latent factors was established using the average variance extracted (AVE) and composite reliability coefficients ( $\rho$ ) which should exceed .500 and .700 , respectively. Discriminant validity is supported when the square-root of the AVE for each latent variable exceeds its correlation coefficient with other latent variables. Adequacy of the hypothesised pattern of relations among the model constructs was established using an overall goodness-of-fit (GoF) index given by the square root of the product of the AVE and average $R^{2}$ for the model (.100, .250, and .360 correspond to small, medium, and large effect sizes, respectively; Tenenhaus, Vinzi, Chatelin, \& Lauro, 2005). Further information on the adequacy of the model is provided by the average path coefficient (APC) and average $R^{2}$ (ARS) coefficient across the model, both of which should be significantly different from zero. In addition, an overall goodness-of-fit index is provided by the average variance inflation factor for model parameters (AVIF), which should be less than 5.000 for a well-fitting model. To verify the robustness of the model parameters (i.e., the path estimates representing relations among the variables), a bootstrapping resampling technique 
with 100 replications was utilised to estimate stable and reliable averaged path estimates and associated significance levels (Kock, 2015).

\section{Results}

\subsection{Preliminary analyses}

The VB-SEM measurement-level statistics were examined to confirm that the latent variables met criteria for construct and discriminant validity. Means, standard deviations, composite reliability coefficients $(\rho)$, AVE, and inter-correlations for primary model variables are presented in Table 1. The pattern of correlations between short term saving behaviour and all other variables, and long term saving behaviour and all other variables were very similar. Further, the correlation between short term and long term saving was high $(r=$ $.692, p<.001)$, suggesting that these two measures were assessing similar constructs. As such, these measures were used to form a single latent variable of saving behaviour. Reliability coefficients exceeded the .700 criterion for all factors and AVE values exceeded the recommended .500 criterion. The only exception to this pattern was the trait self-control factor, which had an AVE that fell below the .500 criterion. This is consistent with previous research which has found poor factor loadings and structure with the same scale (de Ridder, de Boer, Lugtig, Bakker, \& van Hooft, 2011; Maloney, Grawitch, \& Barber, 2012). Findings should be interpreted in light of the inadequate construct validity statistics for this variable, but it should be stressed that the latent factor is determined by the shared variance among the factors and, therefore, is free from measurement error. Given that the highest factor loadings for this factor make reference to inhibition, it is reasonable to assume that this factor represents participants’ trait capacity for impulse control (de Ridder et al., 2011). Factor correlations among the latent variables also indicated no problems with discriminant validity. In all cases, the square root of the AVE for each latent variable approached or exceeded the correlation between the variable and all other variables. 


\subsection{Structural Equation Model}

Standardised parameter estimates for the structural relations among factors in the proposed model are given in Figure 1. Overall, the model indicated adequate model fit with large effect sizes according to multiple fit indexes, $\mathrm{GoF}=0.338$; $\mathrm{APC}=.119, p<.001 ; \mathrm{ARS}=.172, p<$ $.001 ;$ AVIF $=1.374$. In addition, the model accounted for statistically significant amounts of variance in the key dependent variables: intention to save, $R^{2}=.364$, buying impulsiveness, $R^{2}=.232$, and saving behaviour, $R^{2}=.173$. We found few significant effects for demographic variables on study constructs, and effect sizes, on the whole, were relatively modest (see Appendix A). Nevertheless, we retained these variables as predictors of each study construct in our structural equation model to control any potential confounding effects.

Insert Figure 1 here

3.2.1 Direct effects. Focusing on the test of the hypothesised direct effects in the proposed model, there was a significant positive association of intention and saving behaviour, $\beta=-.210, p<.001$; however, buying impulsiveness was not significantly related to saving behaviour, $\beta=-.066, p=.108$. Self-control had a direct positive effect on saving behaviour, $\beta=.176, p<.001$, and intention to save, $\beta=.114, p<.001$, indicating that higher self-control was related to greater intention to save and saving behaviour. Additionally, selfcontrol was negatively related to buying impulsiveness, $\beta=-.283, p<.001$, indicating that greater self-control was associated with less impulsiveness. Saving habits were positively related to intention to save, $\beta=.521, p<.001$, and saving behaviour, $\beta=.080, p=.046$, indicating that a higher automatic tendency to save money was associated with greater intention to save and actual saving behaviour. Additionally saving habit was negatively related to buying impulsiveness, $\beta=-.300, p<.001$, such that a greater automatic tendency to save money was related to lower buying impulsiveness. These effects were present controlling for gender, age, and income. 
3.2.2 Indirect effects. It was also hypothesised that distal constructs in the model would have indirect effects on proximal behavioural outcome variables through the hypothesised mediators. As predicted, there were statistically significant overall indirect effects of selfcontrol, $\beta=.042, p=.011$, and habit, $\beta=.129, p<.001$, on saving behaviour. Tests of partial indirect effects revealed that the partial effect of self-control on saving behaviour through intention, $\beta=.020, p=.004$, was statistically significant and contributed most to the total indirect effect while the partial effect through buying impulsiveness, $\beta=.007, p=.332$, was much smaller and not statistically significant. Examining the partial indirect effects for habit on saving behaviour revealed that the partial effect of habit on saving behaviour through intention, $\beta=.091, p<.001$, was statistically significant and contributed most to the total indirect effect while the partial effect through buying impulsiveness, $\beta=.007, p=.345$, was much smaller and not statistically significant.

3.2.3 Moderation effects. Saving habit strength significantly moderated the relationship between buying impulsiveness and saving behaviour, $\beta=.113, p=.026$. No other moderation effects were significant. Simple slope analyses revealed that at lower levels of habit saving strength (1SD below the mean) greater buying impulsiveness was related to less saving behaviour, $\beta=-.179, t(593)=-2.437, p=.015$. At higher levels of habit strength $(1 S D$ above the mean), there was no relationship between buying impulsiveness and saving behaviour, $\beta$ $=.047, t(593)=0.578, p=.563$; see Figure 2 .

Insert Figure 2 here

\section{Discussion}

This is the first study in which a comprehensive dual-process approach was taken to examine the psychological influences on saving behaviour. Results demonstrated that saving behaviour is directly predicted by intention, self-control, and habit strength. The latter two constructs also had indirect effects on behaviour through intention. Overall, effects of buying 
impulsiveness, representing the impulsive system, did not directly influence saving behaviour. However, buying impulsiveness did have a direct effect on saving behaviour when saving habit strength was low. These findings demonstrate the complexities of saving behaviour and lend support to a dual-process explanation (Hofmann et al., 2008; Strack \& Deutsch, 2004).

Findings of this study align with previous studies showing that intention to save is an important predictor of saving behaviour (Davis \& Hustvedt, 2012; Kidwell \& Turrisi, 2004; Magendans et al., 2016; Shim et al., 2012; Wärneryd, 1999), and previous literature showing the direct relationship between self-control and saving behaviour (Gathergood, 2012), and habit strength and saving behaviour (Loibl et al., 2011). The direct effects of self-control and saving habit were partially explained by the relationship between these variables and saving intention. That is, those with greater self-control or stronger saving habits were also more likely to possess intentions to save money, and intention was associated with actual behaviour. These findings build on previous research that only examined the direct relationship between these variables and behaviour (Loibl et al., 2011; Tangney et al., 2004). Specifically, previous research has suggested that habitual actions operate independently of reflective processes (Bargh, 1994). The current findings suggest a role for both, in which previously acquired habits are associated with intentions to perform a behaviour. This is in line with recent results in other behavioural domains (Allom, Mullan, Cowie, \& Hamilton, 2016; Hagger, Trost, Keech, Chan \& Hamilton, 2017; Hamilton et al., 2017; Hamilton, Orbell, Bonham, Kroon \& Schwarzer, 2017), and current theories of habit (Gardner, 2015), which suggests that these processes can simultaneously or synergistically influence behaviour. People may form 'good' habits in the service of goal intentions, and experience ease of performance as a consequence of habit development, so that self reports reflect consistency between habit and intention (Orbell, in press). 
The finding that habit strength moderated the relationship between impulsivity and behaviour sheds light on the relationship between this impulse control and behaviour in a dual-systems account of saving behaviour. Within dual-process theory having strong habits suggests that the behaviour is likely to be predominantly controlled by habitual, automatic processes. However, the theory also suggests that strong habits may moderate the effects of impulses to engage in behaviours that run counter to the habitual behaviour downwards (Hofmann et al., 2009; Strack et al., 2006). Based on current findings in the context of saving behaviour, it appears that strong habits hinder the impulse to spend. These findings suggest that good habits may protect against counter-habitual impulses.

\subsection{Implications}

Interventions targeting intention to save money may indeed enhance saving behaviour, but previous research suggests intention-focused interventions only have modest effects on actual behaviour (Webb \& Sheeran, 2006). It is important, therefore, that such intervening strategies are used in collaboration with strategies targeting other precursors of saving behaviour as well. For example, the current study findings suggest that self-control and habit indirectly impact saving behaviour through intentions. There have been interventions that have effectively enhanced self-control (for reviews, see: Allom, Mullan, \& Hagger, 2016; Beames, Schofield, \& Denson, in press; van Beurden, Greaves, Smith, \& Abraham, 2016), and habit strength (Lally \& Gardner, 2013; Mullan, Allom, Fayn, \& Johnson, 2014; Orbell \& Verplanken, 2010) to improve behaviour. Such strategies, including monitoring of behaviour and use of environmental cues, are worth exploring in order to enhance people’s saving behaviour and financial health. Moreover, although not directly related to saving behaviour, buying impulsiveness was also shown to be an important part of the saving behaviour process, in that people who were more impulsive with their buying behaviour tended to engage less in saving behaviour but only when their saving habits were 
low. This suggests that habitual saving behaviour may protect against the negative influence of the impulsive system on behaviour and provides further justification to pursue research in habit formation.

\subsection{Limitations}

Participants were recruited through a commercial online recruitment facility and this may have impacted the representativeness of the sample. However, recent studies have pointed to this type of participant being more attentive to instructions and more representative than using undergraduate participant pools (Ramsey, Thompson, McKenzie, \& Rosenbaum, 2016), and generally representative of the population after controlling for certain demographics (Ramsey et al., 2016). Although the demographic profile of the sample indicate a level of diversity with respect to participant ethnicity, as this was a self-selected sample it was not stratified. Future research with stratified sampling is warranted. The SRHI is a self-report measure of habit that relies upon people's meta-cognitive awareness that they perform the same act repeatedly in the same context, do so without making a conscious decision to act, start acting before they realise they are doing so and so on. There has recently been some debate over the extent to which individuals can accurately report on their automatic behaviours (Hagger et al., 2016; Labrecque \& Wood, 2015; Orbell \& Verplanken, 2015). Previous research has shown that 12 -item SRHI scores are associated with specific theoretical processes in habit. SRHI scores correlate with implicit measures of attentional bias to habit cues and prospectively predict non-intended action slips in the presence of cues (Orbell \& Verplanken, 2010). Given the SRHI has been frequently used in past literature and there are currently limited survey alternatives for measuring habit, it was the most suitable measure for the purpose of this study. Future research may benefit from inclusion of alternative measures of automaticity that are not reliant on self-report. Data were collected concurrently; thus, only associations could be examined rather than causal influences. 
Nonetheless, cross-sectional data are important first steps in understanding behavioural processes and allow for larger sample sizes that may otherwise have been lost to attrition (Rabinovich \& Webley, 2007).

\subsection{Conclusions}

The current findings support a dual-process explanation of behaviour that suggests that reflective processes such as the effects of intention on behaviour only provide a partial explanation of behaviour. Other processes of a more impulsive nature need to be considered, and whether the influence of additional factors such as self-control and habit exert indirect effects on behaviour through these systems or moderate the relationship between these constructs and behaviour. These findings highlight the complexity of saving behaviour and suggest that using strategies that target constructs integral to the reflective and impulsive systems are potentially needed to change behaviour in this domain. Developments in the habit formation literature (Mullan, Allom, Fayn, \& Johnston, 2014), in addition to the literature on deliberative behavioural change strategies (Hagger et al., 2016), may provide options for intervention design to successfully change saving behaviour. 


\section{References}

Achtziger, A., Hubert, M., Kenning, P., Raab, G., \& Reisch, L. (2015). Debt out of control: The links between self-control, compulsive buying, and real debts. Journal of Economic Psychology, 49, 141-149.

Ajzen, I. (1991). The theory of planned behavior. Organizational behavior and human decision processes, 50, 179-211.

Allom, V., \& Mullan, B. (2012). Self-regulation versus habit: The influence of self-schema on fruit and vegetable consumption. Psychology \& Health, 27, 7-24. doi: http://dx.doi.org/10.1080/08870446.2011.605138

Allom, V., Mullan, B., Clifford, A., \& Rebar, A. (2018). Understanding supplement use: an application of temporal self-regulation theory. Psychology, health \& medicine, 23(2), 178-188.

Allom, V., Mullan, B., Cowie, E., \& Hamilton, K. (2016). Physical Activity and Transitioning to College: The Importance of Intentions and Habits. American Journal of Health Behavior, 40, 280-290. doi: doi.org/10.5993/AJHB.40.2.13

Allom, V., Mullan, B., \& Hagger, M. (2016). Does inhibitory control training improve behavior regulation? A meta-analysis. Health Psychology Review, 10, 168-186.

Allom, V., Panetta, G., Mullan, B., \& Hagger, M. S. (2016). Self-report and behavioural approaches to the measurement of self-control: Are we assessing the same construct? Personality and Individual Differences, 90, 137-142.

Bargh, J. (1994). The Four Horsemen of automaticity: awareness, efficiency, intention, and control in social cognition. In R. Wyer Jr. \& T. Srull (Eds.), Handbook of Social Cognition (pp. 1-40): Hillsdale, NJ: Erlbaum. 
Baumeister, R. F., Vohs, K. D., \& Tice, D. M. (2007). The strength model of self-control. Current Directions in Psychological Science, 16, 351-355. doi: 10.1111/j.14678721.2007.00534.x

Bayley, G., \& Nancarrow, C. (1998). Impulse purchasing: a qualitative exploration of the phenomenon. Qualitative Market Research: An International Journal, 1, 99-114.

Beames, J., Schofield, T., \& Denson, T. (in press). A Meta-analysis of Improving Self-control with Practice. In D. de Ridder, M. Adriaanse \& K. Fujita (Eds.), Handbook of selfcontrol in health and well-being: Routledge.

Beatty, S. E., \& Ferrell, M. E. (1998). Impulse buying: modeling its precursors. Journal of retailing, 74, 169-191.

Black, N., Mullan, B., \& Sharpe, L. (2017). Predicting heavy episodic drinking using an extended temporal self-regulation theory. Addictive behaviors, 73, 111-118.

Blau, P. M. (1994). Structural contexts of opportunities. Chicago, Illinois: University of Chicago Press.

Davis, K., \& Hustvedt, G. (2012). It’s a matter of control: Saving for retirement. International Review of Social Sciences and Humanities, 3, 248-261.

de Ridder, D. T., de Boer, B. J., Lugtig, P., Bakker, A. B., \& van Hooft, E. A. (2011). Not doing bad things is not equivalent to doing the right thing: Distinguishing between inhibitory and initiatory self-control. Personality and Individual Differences, 50, 1006-1011. doi: 10.1016/j.paid.2011.01.015

Dew, J. P. (2016). Family Finances. In C. Shehan (Ed.), The Wiley Blackwell Encyclopedia of Family Studies.

Fisher, P. J. (2010). Gender differences in personal saving behaviors. Journal of Financial Counseling and Planning, 21, 14. 
Fisher, P. J., \& Anong, S. T. (2012). Relationship of saving motives to saving habits. Journal of Financial Counseling and Planning, 23.

Friese, M., \& Hofmann, W. (2009). Control me or I will control you: Impulses, trait selfcontrol, and the guidance of behavior. Journal of Research in Personality, 43, 795805. doi: 10.1016/j.jrp.2009.07.004

Friese, M., Hofmann, W., \& Wänke, M. (2008). When impulses take over: Moderated predictive validity of explicit and implicit attitude measures in predicting food choice and consumption behaviour. British Journal of Social Psychology, 47, 397-419.

Gathergood, J., \& Weber, J. (2014). Self-control, financial literacy \& the co-holding puzzle. Journal of Economic Behavior \& Organization, 107, 455-469.

Gardner, B. (2015). A review and analysis of the use of 'habit'in understanding, predicting and influencing health-related behaviour. Health Psychology Review, 9, 277-295. doi: 10.1080/17437199.2013.876238

Gardner, B., Abraham, C., Lally, P., \& de Bruijn, G.-J. (2012). Towards parsimony in habit measurement: Testing the convergent and predictive validity of an automaticity subscale of the Self-Report Habit Index. International Journal of Behavioral Nutrition and Physical Activity, 9, 102.

Gathergood, J. (2012). Self-control, financial literacy and consumer over-indebtedness. Journal of Economic Psychology, 33, 590-602.

Grable, J. E. (2000). Financial risk tolerance and additional factors that affect risk taking in everyday money matters. Journal of Business and Psychology, 14, 625-630.

Grable, J. E., \& Lytton, R. (1997). Determinants of retirement savings plan participation: A discriminant analysis. Personal Finances and Worker Productivity, 1, 184-189. 
Hagger, M., Rebar, A., Mullan, B., Lipp, O., \& Chatzisarantis, N. (2015). The Subjective Experience of Habit Captured by Self-Report Indexes May Lead to Inaccuracies in the Measurement of Habitual Action ～Health Psychology Review, 9, 296-302.

Hagger, M. S., Trost, N., Keech, J. J., Chan, D. K., \& Hamilton, K. (2017). Predicting sugar consumption: application of an integrated dual-process, dual-phase model. Appetite, 116, 147-156.

Hagger, M. S., Luszczynska, A., de Wit, J., Benyamini, Y., Burkert, S., Chamberland, P.-E., . . French, D. P. (2016). Implementation intention and planning interventions in Health Psychology: Recommendations from the Synergy Expert Group for research and practice. Psychology \& Health 1-26. doi: 10.1080/08870446.2016.1146719

Hamilton, K., Kirkpatrick, A., Rebar, A., \& Hagger, M. S. (2017). Child sun safety: Application of an Integrated Behavior Change model. Health Psychology, 36(9), 916.

Hamilton, K., Orbell, S., Bonham, M., Kroon, J., \& Schwarzer, R. (2017). Dental flossing and automaticity: a longitudinal moderated mediation analysis. Psychology, health \& medicine, 1-9.

Hershey, D. A., Jacobs-Lawson, J. M., McArdle, J. J., \& Hamagami, F. (2007). Psychological foundations of financial planning for retirement. Journal of Adult Development, 14, 26-36.

Hofmann, W., Friese, M., \& Strack, F. (2009). Impulse and Self-Control From a DualSystems Perspective. Perspectives on Psychological Science, 4, 162-176.

Hofmann, W., Friese, M., \& Wiers, R. W. (2008). Impulsive versus reflective influences on health behavior: A theoretical framework and empirical review. Health Psychology Review, 2, 111-137. 
Juraskova, I., O’Brien, M., Mullan, B., Bari, R., Powell, R., \& McCaffery, K. (2012). HPV vaccination and the effect of information framing on intentions and behaviour: An application of the theory of planned behaviour and moral norm. International Journal of Behavioral Medicine, 19, 518-525. doi: http://dx.doi.org/10.1007/s12529-011-9182

Kidwell, B., \& Turrisi, R. (2004). An examination of college student money management tendencies. Journal of Economic Psychology, 25, 601-616.

Kock, N. (2015). WarpPLS 5.0 User Manual. Laredo, Texas: ScriptWarp Systems.

Kothe, E., Mullan, B., Sainsbury, K., \& Smith, L. (2015). Explaining the intention-behaviour gap in gluten free diet adherence: The moderating roles of habit and perceived behavioural control. Journal of Health Psychology, 20, 580-591.

Labrecque, J. S., \& Wood, W. (2015). What measures of habit strength to use? Comment on Gardner (2015). Health Psychology Review, 9(3), 303-310.

Lally, P., \& Gardner, B. (2013). Promoting habit formation. Health Psychology Review, 7, S137-S158.

Lally, P., Wardle, J., \& Gardner, B. (2011). Experiences of habit formation: A qualitative study. Psychology, Health \& Medicine, 16, 484-489. doi: $10.1080 / 13548506.2011 .555774$

Loibl, C., Kraybill, D. S., \& DeMay, S. W. (2011). Accounting for the role of habit in regular saving. Journal of Economic Psychology, 32, 581-592.

Lynch, J. G., Netemeyer, R. G., Spiller, S. A., \& Zammit, A. (2010). A generalizable scale of propensity to plan: the long and the short of planning for time and for money. Journal of Consumer Research, 37, 108-128.

Magendans, J., Gutteling, J., \& Zebel, S. (2016). Psychological determinants of financial buffer saving: the influence of financial risk tolerance and regulatory focus. Journal of risk research 1-18. 
Maloney, P. W., Grawitch, M. J., \& Barber, L. K. (2012). The multi-factor structure of the Brief Self-Control Scale: Discriminant validity of restraint and impulsivity. Journal of Research in Personality, 46, 111-115.

McEachan, R. R. C., Conner, M., Taylor, N. J., \& Lawton, R. J. (2011). Prospective prediction of health-related behaviours with the Theory of Planned Behaviour: a meta-analysis. Health Psychology Review, 5, 97-144.

Mullan, B., Allom, A., Fayn, K., \& Johnston, I. (2014). Building habit strength: A pilot intervention designed to improve food-safety behavior. Food Research International, 66, 274-278.

Mullan, B., Allom, V., Brogan, A., Kothe, E., \& Todd, J. (2014). Self-regulation and the intention behaviour gap: Exploring dietary behaviours in university students. Appetite, 73, 7-14. doi: http://dx.doi.org/10.1016/j.appet.2013.10.010

Mullan, B., Allom, V., Fayn, K., \& Johnson, I. (2014). Building habit strength: An intervention designed to improve food-safety behavior. Food Research International, http://www.sciencedirect.com/science/article/pii/S0963996914006279.

Mullan, B., Henderson, J., Kothe, E., Allom, V., Orbell, S., \& Hamilton, K. (2016). The role of habit and perceived control on health behavior among pregnant women. American journal of health behavior, 40(3), 291-301.

Orbell, S. (2007). Motivational Models and Volitional Processes in the Promotion of Health Behaviors.

Orbell, S., \& Verplanken, B. (2010). The automatic component of habit in health behavior: Habit as cue-contingent automaticity. Health psychology, 29(4), 374.

Orbell, S., \& Verplanken, B. (2015). The strength of habit. Health psychology review, 9(3), 311-317. 
Prelec, D., \& Loewenstein, G. (1991). Decision making over time and under uncertainty: A common approach. Management science, 37, 770-786.

Rabinovich, A., \& Webley, P. (2007). Filling the gap between planning and doing:

Psychological factors involved in the successful implementation of saving intention. Journal of Economic Psychology, 28, 444-461.

Ramsey, S. R., Thompson, K. L., McKenzie, M., \& Rosenbaum, A. (2016). Psychological research in the internet age: The quality of web-based data. Computers in Human Behavior, 58, 354-360.

Rich, A., Brandes, K., Mullan, B., \& Hagger, M. S. (2015). Theory of planned behavior and adherence in chronic illness: a meta-analysis. Journal of behavioral medicine 1-16.

Richardson, T., Elliott, P., \& Roberts, R. (2013). The relationship between personal unsecured debt and mental and physical health: a systematic review and metaanalysis. Clinical psychology review, 33, 1148-1162.

Rook, D. W., \& Fisher, R. J. (1995). Normative influences on impulsive buying behavior. Journal of Consumer Research 305-313.

Shim, S., Serido, J., \& Tang, C. (2012). The ant and the grasshopper revisited: The present psychological benefits of saving and future oriented financial behaviors. Journal of Economic Psychology, 33, 155-165.

Sniehotta, F. F., Presseau, J., \& Araújo-Soares, V. (2014). Time to retire the theory of planned behaviour. Health Psychology Review, 8, 1-7.

Stawski, R. S., Hershey, D. A., \& Jacobs-Lawson, J. M. (2007). Goal clarity and financial planning activities as determinants of retirement savings contributions. The International Journal of Aging and Human Development, 64, 13-32.

Strack, F., \& Deutsch, R. (2004). Reflective and impulsive determinants of social behavior. Personality and Social Psychology Review, 8, 220-247. 
Strack, F., Werth, L., \& Deutsch, R. (2006). Reflective and Impulsive Determinants of Consumer Behavior. Journal of Consumer Psychology, 16, 205-216. doi: http://dx.doi.org/10.1207/s15327663jcp1603 2

Tangney, J. P., Baumeister, R. F., \& Boone, A. L. (2004). High self-control predicts good adjustment, less pathology, better grades, and interpersonal success. Journal of personality, 72, 271-324.

Tay, L., Batz, C., Parrigon, S., \& Kuykendall, L. (2016). Debt and Subjective Well-being: The Other Side of the Income-Happiness Coin. Journal of Happiness Studies 1-35.

Tenenhaus, M., Vinzi, V. E., Chatelin, Y.-M., \& Lauro, C. (2005). PLS path modeling. Computational statistics \& data analysis, 48, 159-205.

van Beurden, S., Greaves, C., Smith, J., \& Abraham, C. (2016). Techniques for modifying impulsive processes associated with unhealthy eating: A systematic review. Health Psychology, 35, 793-806. doi: 10.1037/hea0000337

Verplanken, B., \& Orbell, S. (2003). Reflections on past behavior: A self-report index of habit strength. Journal of Applied Social Psychology, 33, 1313-1330. doi: 10.1111/j.1559-1816.2003.tb01951.x

Vohs, K. D., \& Faber, R. J. (2007). Spent resources: Self-regulatory resource availability affects impulse buying. Journal of Consumer Research, 33, 537-547.

Wärneryd, K. E. (1999). The psychology of saving: A study on economic psychology. Northampton, Massachusetts: Edward Elgar Publishing.

Webb, T. L., \& Sheeran, P. (2006). Does changing behavioral intentions engender behavior change? A meta-analysis of the experimental evidence. Psychological Bulletin, 132, 249-268.

Yuh, Y., \& DeVaney, S. A. (1996). Determinants of couples’ defined contribution retirement funds. Financial Counseling and Planning, 7, 31-38. 
Yuh, Y., \& Hanna, S. D. (2010). Which households think they save? Journal of Consumer Affairs, 44, 70-97. 